\title{
TOO MANy MigRANTS, TOO FEW SERVICES: A MODEL OF DECISION-MAKING ON IMMIGRATION AND INTEGRATION WITH CULTURAL DISTANCE
}

\author{
HARRIE A. A. VERBON \\ LEX MEIJDAM
}

CESIFO WORKING PAPER NO. 1268

CATEgORY 1: Public FinANCE

SEPTEMBER 2004

Presented at CESifo Conference on Migration and the Welfare State, NOVEMBER 2003

An electronic version of the paper may be downloaded

- from the SSRN website:

http://SSRN.com/abstract $=601321$

- from the CESifo website:

www.CESifo.de 


\title{
TOO MANy Migrants, TOO FEW SERVICES: A MODEL OF DECISION-MAKING ON IMMIGRATION AND INTEGRATION WITH CULTURAL DISTANCE
}

\begin{abstract}
In this paper we model the demand for immigrants as a trade-off native voters face between having services, produced by unskilled and non-assimilated immigrants, and experiencing disutility due to the immigrant workers having a culture different from the native culture. Immigrants decide whether to integrate into the native culture. If they don't, they produce services. Assimilated immigrants take on skilled jobs. At the political level natives choose the number of immigrants that can be allowed, given some fixed price for services. We show that, at the assumed price, it is never optimal for natives to have equilibrium or unemployment in the service sector. Market forces then lead to higher service prices, implying that the initially allowed number of immigrants is too large.
\end{abstract}

JEL: D72, F22.

\author{
Harrie A. A. Verbon \\ Tilburg University \\ Department of Economics \\ P.O.Box 90153 \\ 5000 LE Tilburg \\ The Netherlands \\ H.A.A.Verbon@uvt.nl
}

\author{
Lex Meijdam \\ Tilburg University \\ Department of Economics \\ P.O.Box 90153 \\ 5000 LE Tilburg \\ The Netherlands
}

This paper has benefited from comments of the participants of the CES/Ifo Conference on Migration and the Welfare State, held in Munich, November 7-8, 2003. 


\section{Introduction}

In Europe, the immigrant population has reached unprecedented high levels, amounting to about $10 \%$ in countries such as, e.g., France, Germany, Austria, and the Netherlands. Two characteristics of immigrant workers in Europe stand out. First, compared to native workers, they appear to be concentrated in low-skilled, low-paid jobs. Second, immigrants are geographically concentrated in specific areas of the immigrant country, in particular, in the big cities. For instance, in the four largest cities in the Netherlands, 30\% of the residents belong to the non-native population (Dagevos et al., 2003).

Lazear (1999) asserts that assimilation of natives is less likely when the emigrants' culture is strongly represented in the receiving country. This makes their position on the labor market more vulnerable as they will then tend to be admitted to the "secondary labor market" only where flat low wages are paid and mobility to better paid jobs is low (See, Dickens and Lang, 1985, for an early empirical appraisal of the existence of dual labor markets).

Recently, the increasing number of immigrants has affected the political climate in the receiving countries to a large extent. An increasing anxiety has arisen among natives, fed by the fear that a too large stock of non-assimilating non-natives can undermine the social norms natives adhere to. It is an indisputable fact that different societies have different social norms, and immigrants may bring along social norms which conflict with those of the native populations. People (both immigrants and natives) can feel disutility when they are confronted with social norms that contradict their own norms ${ }^{1}$.

In this paper we model the above described status of immigrants, and the attitude of natives towards immigrants in a two-sector economy with a primary sector producing goods using skilled labor, and a secondary sector, producing services only using unskilled labor. The labor force consists of immigrant and native workers. Immigrants decide whether to integrate into the native culture. If immigrants do not assimilate, they can only

\footnotetext{
${ }^{1}$ It goes without saying that the individual attitudes towards the cultural effects of immigration may be diverse. Some native individuals might have a taste for multiculturalism and welcome immigration as contributing to new ideas and opening up a variety of cultures to be enjoyed, while others prefer a more
} 
find a job in the secondary services sector. If they do assimilate, they will lose utility due to losing their own culture, but they will gain in income, as they will become skilled workers in the goods sector. Native workers are all skilled so they depend upon nonassimilating immigrants to produce services. However, natives experience disutility if immigrant workers have a culture different from their own culture (see Hillman (2002) for an analogous modeling).

Natives make the following decisions. At the individual level they decide on the consumption of goods and services. At the macro political level they choose the number of immigrants that can be allowed into the country ${ }^{2}$. In making this political decision the native workers take the endogenous assimilation decision of immigrants into account, but they take the price of services as exogenously given ${ }^{3}$.

Our basic result is that, at the assumed price for services, it is never optimal for natives to allow in a number of immigrants that implies equilibrium or unemployment in the service sector. In other words, the political demand for immigrants will always be such that services are rationed. The intuition of this result is as follows. In the market equilibrium for services, the marginal benefit of consuming services is equal to its marginal costs. However, as natives in demanding immigrants, not only take account of the marginal costs and benefits of consuming services, but also include the cultural burden non-assimilated immigrants impose upon them, their political demand for immigrants will imply that the marginal benefit of services consumption is higher than the marginal costs.

In a market economy prices will increase, following the initial rationing equilibrium. Assuming that it will not possible to send off immigrants who initially were

homogeneous society (see Mayda, 2004). We, however, assume that the 'average' native voter has a distaste for cultural differences.

${ }^{2}$ Modelling the demand for immigration as a result of utility maximization has obtained some popularity in the public-choice oriented literature. For example, Benhabib (1996) derives the demand for immigrants as a function of their wealth compared to the wealth of the median voter. In Haupt and Peters (1998) natives demand immigrants in order to get lower social-security taxes or higher social-security benefits.

${ }^{3}$ Native voters are well aware of some of the economic consequences of immigration as Mayda (2004) has demonstrated. She finds that political attitudes toward immigrants are related to labour-market concerns and cultural considerations. These effects thus do not pertain to prices of specific consumption goods. Labour-market concerns are a factor in our model as far as the rate of unemployment among immigrants is involved. As we assume exogenous wages, crowding on the labour market, which is usually one of the culprits for anti-immigration attitudes of natives, does not play a role here. On the other hand, the fact that 
allowed to enter the country, the consequence of flexible prices will be that the number of immigrants in a country is too large. Another undesired consequence of services price increases can be that the formal services sector will be replaced by an informal sector, where services are produced at home or in the shadow economy. This will lead to unemployment for the non-integrated immigrants.

Native voters will, under certain circumstances, support policies aimed at ameliorating the assimilation decision by immigrants. Within our model we will analyze two such policies. A first policy option to analyze within the model is focused on residential location of immigrants. An explicit policy goal in European countries is to "spread" immigrants, instead of having them concentrated in a limited number of areas.

The idea is that if immigrants are not concentrated in specific residential areas, but are dispersed among the native population, the utility loss of assimilation will be lower for the immigrants. This is in line with empirical evidence that immigrants who tend to cluster together will assimilate less, and have a larger inclination to stick to their own social norms (Kónya, 2003). The spreading policy as we model it, is a free lunch in the sense that no costs are involved. Naturally, this implies some bias in favor of such a policy, contrary to a policy that involves costs like subsidies on integration costs. Given this it appears that in our model a spreading policy will be supported even if services are rationed. As a second policy option we consider whether native workers will support a tax-financed policy aimed at decreasing the financial costs of assimilation.

\section{The model}

A two-sector economy is assumed. One sector is producing goods using skilled labor, $L$, according to a linear production function $F=F(L)$. The other sector (to be called the service sector) is only using unskilled labor, $U$, according to $G=\beta U$. The labor force consists of immigrants $I=U+M$ and native workers $N$, where $U(M)$ is the number of non-assimilated (assimilated) immigrants. Immigrants who have decided to integrate into the native culture, will be employed as skilled workers in the goods sector. Non-

skilled labour becomes relatively more scarce due to immigration of unskilled workers does not affect wages either. 
assimilated immigrants remain unskilled and will be employed in the service sector. Native workers are always skilled.

Prices in the service sector are at a level $p$, that the voters assume to be fixed, and we assume, for simplicity, that this price is linked to the wage earned in this sector by $p=w^{U} / \beta$.

At the individual level natives decide on the counsumption of goods and services. At the macro political level they choose the number of immigrants that can be allowed into the country. They decide on the basis of the following utility function:

$$
V^{N}=\log (f)+\delta \log (g)-q(s) \log (U)
$$

where $f$ and $g$ are individual consumption of goods and services, respectively. The last term indicates the disutility native individuals derive from cultural differences with the non-assimilated immigrant population. The parameter $s$ with $0 \leq s \leq 1$ indicates the spreading policy with $s=1$ indicating the absence of such a policy, $s=0$ implies a maximal spreading policy. The function $q(s)$ indicates to what degree such a policy affects the disutility of the natives. It is assumed that $q^{\prime}(s)>0$, i.e. the disutility the natives derive from living with immigrants will be larger at a less intensive spreading policy.

Individual migrants decide on the consumption of goods and services, and whether to adapt to the native culture, or not. Immigrants are heterogeneous with respect to their individual attachment to their native culture. The utility function of a type $j$ immigrants reads ${ }^{4}$

$$
V_{j}^{I}=\log (f)+\delta \log g+\rho_{j}(1-c) s U^{\gamma} \quad \text { with } 0 \leq \rho_{j} \leq 1
$$

\footnotetext{
${ }^{4}$ Notice the similarity of this specification with the so-called attachment-to-home models, proposed by Mansoorian and Myers (1993).
} 
The last term indicates attachment to immigrant culture where the parameter $\rho_{j}$ indcates the weight the individual places on culture, and the parameter $\gamma(<1)$ indicates the economies-of-scale of enjoying culture with fellow non-assimilated immigrants.. The variable $c$ represents the culture to be adopted by the immigrants, with $c=0(c=1)$ indicating assimilation to their own (native) culture. Notice that in the absence of spreading policy $(s=1)$, the utility derived from sticking to immigrant culture $(c=0)$ increases with the number of non-integrated immigrants. This reflects that if the government does not intervene in the location of immigrants, the tendency to gather together will reduce the incentives for immgrants to adapt to native culture. Individuals will enjoy their own culture more if they can share their feelings with 'enough' fellow non-natives. If a maximal spreading policy prevails $(s=0)$ attachment to culture does not affect utility, and the immigrant will adopt native culture $(c=1)$ as a result.

At the assumed price of services, equilibrium is not guaranteed. To derive under which conditions equilibrium on the services market occurs, assume that the number of integrated immigrants equals $M=\rho I$, where the parameter $\rho$ indicates the percentage of the immigrants deciding to integrate into native culture. Non integrated immigrants $U=(1-\rho) I$ keep working in the services sector. The individual demand for services equals $g=\frac{\delta}{1+\delta} y / p$, where $y$ is net income of an individual. As a result, rationing (unemployment) on the service market will occur if and only if ${ }^{5}$,

$$
w^{U} U<(>) \delta w^{N}(\mathrm{~N}+\mathrm{M})
$$

If wage in the service (goods) sector, $w^{U}\left(w^{N}\right)$, is "too" large ("too" small), or if the utility weight on services, $\delta$, is not large enough, unemployment of immigrant labor will occur, while demand will be rationed in the reversed cases. Moreover, the unemployment

\footnotetext{
${ }^{5}$ Notice that equilibrium on the service market requires $\beta U=\frac{\delta}{1+\delta} \frac{w^{U}}{p} U+\frac{\delta}{1+\delta} \frac{w^{N}}{p}(\mathrm{~N}+\mathrm{M})$. Inserting the definition $\beta=\mathrm{w}^{\mathrm{U}} / p$ gives as the condition for equilibrium $w^{U} U=\delta w^{N}(\mathrm{~N}+\mathrm{M})$.
} 
regime will be more likely if a relatively low number of immigrants assimilate $(U$ is , large').

\section{Assimilation}

Immigrants decide whether or not to assimilate, i.e. $c=0$, or $c=1$. As the immigrants are heterogeneous, some individuals can be expected to integrate, and some not. As the assimilation choice is, moreover, affected by the prevailing market regime, we consider the rationing and unemployment regime in turn.

\section{Rationing regime}

Under rationing the number of services is fixed for every individual, at $\bar{g}$ say ${ }^{6}$, which follows from $\bar{g}=\frac{\beta U}{I+N}$. Assimilation means that the immigrants will become a skilled worker with the associated higher wage $w^{N}$. On the other hand, assimilation involves a cost equal to $K$. Indicating the immigrants" wage, dependent on the assimilation choice by $w^{I}(c)$, and inserting the consumption choice for $f$ and $g$ into the utility function gives the immigrants' utility as a function of culture only,:

$$
V_{j}^{I}(c)=\log \left(w^{I}(c)-K c-p \bar{g}\right)+\delta \log \bar{g}+\rho_{j}(1-c) s U^{\gamma}
$$

where $w^{I}(c)=w^{U}$ if $c=0$, and $w^{I}(c)=w^{N}$ if $c=1$. From this it can be concluded that an immigrant with a utility weight for culture equal to $\rho_{\mathrm{j}}$ will adapt to native culture, if and only if the following inequality holds:

$$
\rho_{j}<\hat{\rho} \equiv \frac{1}{s} U^{-\gamma} \log \left(\frac{w^{N}-K-p \bar{g}}{w^{u}-p \bar{g}}\right)
$$


For a given spreading policy $s$, and for given wages and integration costs, $K$, the immigrants with an attachment to their own culture smaller than the critical value $\hat{\rho}$ choose to assimilate, while all other immigrants decide not to assimilate. The decision to assimilate is determined by the relative gain in net expenditures on goods, and the number of immigrants. Given a uniform distribution of culture weights on the interval $[0,1]$, the number of assimilated immigrants equals $M=\hat{\rho} I$, while $U=(1-\hat{\rho}) I$. Using these definitions, it can be derived that the relationship between $\hat{\rho}$ and $I$ is given by:

$$
\hat{\rho}(1-\hat{\rho})^{\gamma}=\frac{1}{s} I^{-\gamma} \log \left(\frac{w^{N}-K-p \bar{g}}{w^{u}-p \bar{g}}\right)
$$

It will be shown in the Appendix that given a restriction on the parameter $\gamma^{7}$, and with a large enough number of immigrants, $I$, the critical value of $\rho$ will decrease with an increasing number of immigrants, i.e. $d \hat{\rho} / d I$ is negative ${ }^{8}$. In that case, it holds that $0<d U / d I=(1-\hat{\rho})-I(\partial \hat{\rho} / \partial I)<1$. In words, if the number of immigrants is relatively large, increasing the number of migrants will lead to a lower degree of assimilation, as measured by $\hat{\rho}$. As a result, the number of non-assimilated migrants will increase along with a higher number of immigrants, although not one-for-one.

\section{Unemployment regime}

Unemployed immigrants are supposed to receive a benefit equal to the unskilled wage. This benefit is financed by a lump-sum tax $\tau$ on skilled workers. The indirect utility of an immigrant as a function of the culture choice, $c$, reads:

$$
V_{j}^{I}(c)=(1+\delta) \log \left(w^{I}(c)-\tau c-K c\right)+\rho_{j}(1-c) s U^{\gamma}
$$

\footnotetext{
${ }^{6}$ The results would not be affected if we had made the assumption that the number of rationed services to consumers is not uniform, but depends e.g. on their income.

${ }^{7}$ The restriction is $\gamma<(1-\rho) / \rho$ which we will assume to hold.

${ }^{8}$ Notice that this implies that if the number of non assimilated immigrants is low, allowing in immigrants may lead to a higher degree of assimilation. For a large number of non assimilated immigrants, on the other hand, allowing in more immigrants will unambiguously imply to lower the relative degree of assimilation. We will assume the latter condition to hold in the sequel. So, our model has the property, first described by Lazear (1999) that clustering together by immigrants makes their assimilation less likely.
} 
and the assimilation choice is determined by the inequality:

$$
\rho_{j}<\tilde{\rho} \equiv \frac{1+\delta}{s} U^{-\gamma} \log \left(\frac{w^{N}-\tau-K}{w^{u}}\right)
$$

Equation (8) is saying that the net wage increase following assimilation, taking the assimilation costs into account, should be large enough to make a choice for assimilation worth while. Analogous to equation (6), it holds that

$$
\tilde{\rho}(1-\tilde{\rho})^{\gamma}=\frac{1+\delta}{s} I^{-\gamma} \log \left(\frac{w^{N}-\tau-K}{w^{u}}\right)
$$

Equation (9) implies that $d \tilde{\rho} / d I$ is negative, and $0<d U / d I<1$.

Notice that given the assumption that low-skilled workers do not pay the unemployment tax, the unemployment regime itself is a hindrance to assimilation due to the tax rate. If the number of immigrants increases under the unemployment regime the critical parameter $\tilde{\rho}$ decreases, i.e. immigrants assimilate less because the cultural factor of enjoying their culture with more like-minder persons has increased in value and the net skilled wage has decreased due to the higher unemployment tax.

\section{Immigration policy}

Immigration policy will differ according to the prevailing regime. Under rationing a tendency to allow more immigrants to enter might exist, in order to increase the utility of consuming services, while such a tendency will not exist when there is unemployment of immigrants. We consider rationing and unemployment in turn.

\section{Rationing regime}

Under the rationing regime the natives' indirect utility function reads,

$$
V^{N}=\log \left(w^{N}-p \bar{g}\right)+\delta \log \bar{g}-q(s) \log U
$$


The natives in deciding on preferred migration take the effect of the number of migrants on the assimilation choice, reflected by a change in $\hat{\rho}$ into account. Optimal immigration follows from

$$
\frac{d V^{N}}{d I}=\left(\frac{\delta w^{N}-(1+\delta) p \bar{g}}{\left(w^{N}-p \bar{g}\right) \bar{g}}\right) \frac{d \bar{g}}{d I}-\frac{q(s)}{U} \frac{d U}{d I} \leq 0
$$

The term in big brackets has a positive sign as long as rationing occurs. It describes the effect on the utility of consuming goods and services, while the second term is the cultural effect of immigration policy. As $\frac{d U}{d I}>0$, it follows that the demand for immigrants is positive if

$$
\left(\frac{\left(\delta w^{N}-(1+\delta) p \bar{g}\right)}{\left(w^{N}-p \bar{g}\right) \bar{g}}\right) \frac{d \bar{g}}{d U}-\frac{q(s)}{U} \geq 0
$$

Notice that at the desired number of immigrants the rationing regime should hold. This can be seen easily by inserting the demand for services under equilibrium into condition (12) to get $-q(s) / U$. Lifting the rationing constraint implies that the marginal benefit of service consumption equals its marginal cost. However, for native workers, this obviously cannot be individually optimal as the cultural disutility that non assimilated immigrants impose upon them, should be included as well in determining the desired consumption of services.

\section{Unemployment regime}

Given that, as we just saw, an optimal immigration policy will lead to rationing, it should follow that under an unemployment regime immigrants should not be allowed, i.e. that $d V^{N} / d I<0$. This is easily shown to be true. Under the unemployment regime immigration policy follows from maximising:

$$
V^{N}=(1+\delta) \log \left(w^{N}-\tau\right)-q(s) \log U
$$


which gives:

$$
\frac{d V^{N}}{d I}=-\frac{1+\delta}{w^{N}-\tau} \frac{d \tau}{d I}-\frac{q(s)}{U} \frac{d U}{d I} \leq 0
$$

As $\quad d \tau / d I>0$ and $d U / d I>0$ it immediately follows that $d V^{N} / d I<0$. A rational immigration policy cannot lead to unemployment among immigrants. The intuition is obvious. Immigration in an unemployment regime leads to a larger number of unskilled workers, implying a higher cultural disutility and a higher tax rate, but no higher utility from consuming services, as additional immigrants do not lead to higher services production.

Figure 1. Political and market equilibrium

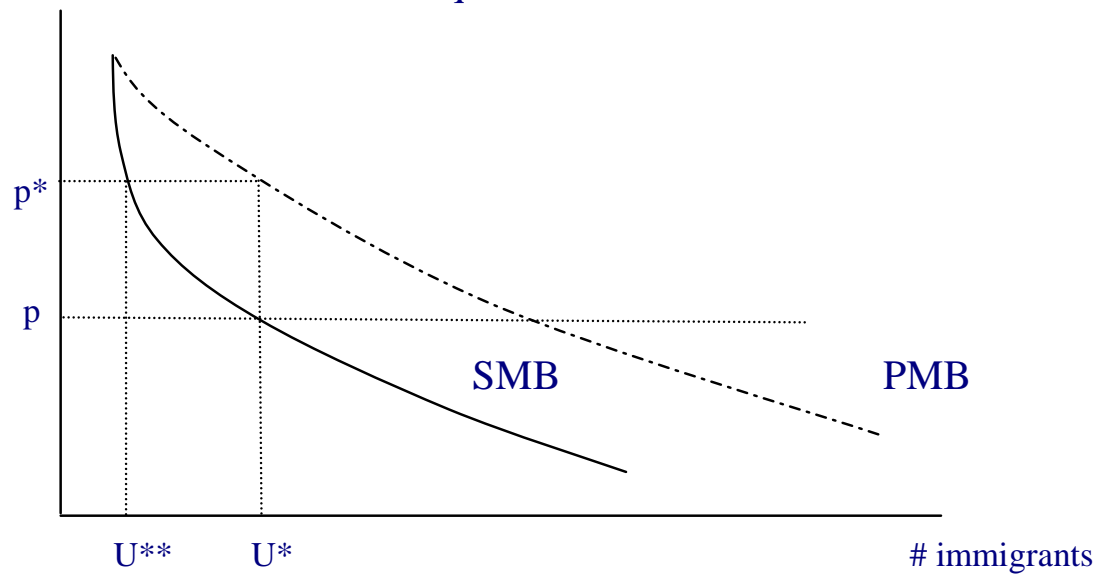

\section{Market forces}

We have as a first result that an equilibrium in the market for services, where private marginal benefits and marginal costs are equal, cannot be politically optimal for native workers: the disutility emerging from the cultural distance with the marginal nonassimilated immigrant is not taken account of in market equilibrium. Figure 1 illustrates this. In politics the social marginal benefit (SMB) of unskilled immigrants is equated to the current price $p$, implying that the optimal number of non-assimilated immigrants 
equals $U^{*}$. On the service market, however, excess demand will arise as individuals are not able to buy services until the private marginal benefits of consumption (PMB) are equal to the price. Given that prices are flexible there will be a tendency for prices to increase. Equilibrium in the service market will be restored when the price equals $p^{*}$. At this price, however, the desired number of non- assimilated immigrants has gone down to $U^{* *}$. So market forces cause the initially allowed number of migrants to become too large.

\section{Unemployment}

Our model thus far predicts that market forces will lead to a too high number of immigrants. However, it does not predict unemployment: all non-assimilated immigrants will be employed in the service sector. In actual fact the unemployment rate among immigrants is higher than among natives. This phenomenon can be fitted into our model if we take account of the well-known fact that a sizeable informal services sector exists, where self-production takes place, or where service sector workers are supplying services at prices below the formal price. The relative size of the informal sector is sensitive to price changes in the formal sector. In particular, it might be the case that there is a maximum to the price of services. That is, from some level of the price onwards the formal demand for services will decrease to zero, as home production is cheaper than purchasing services on the market. So above this maximum price, the formal sector will be completely replaced by the informal sector. As a result then of course all nonassimilated immigrants will become unemployed. This may happen in our model when market forces, following rationing on the service market at the initial price, push the market price to the maximum price of services. If this maximum price is between the price $p$ and $p *$ in Figure 1, unemployment of service sector workers will be the result.

\section{Integration Policies}

From the previous section we conclude that, at a given price for services, an optimal immigration policy at a given price will not imply equilibrium but rationing on the service market. Subsequently, market forces will lead to an increase in service price, and, 
from the perspective of the native voters, the number of immigrants that was considered optimal with the lower price, will then be considered as too high. This may go along with substantial unemployment amongst non-assimilated migrants when market forces push the price of services to a level where home production becomes cheaper than buying on the market. In actual fact, unemployment among immigrants is in many European countries larger than unemployment among the natives and there is an increasing concern in politics about the large number of non-assimilated migrants. This indicates that, indeed, it is difficult to allow in the optimal number of migrants, and that a tendency to overshoot the admittance of immigrants can be observed. Therefore, it is obviously of interest to consider policies aimed at integrating the immigrants into the native culture, as this can provide a utility gain for the natives.

\section{Spreading policies}

In some countries, notably the Netherlands, a policy of spreading the location of immigrants among the native population is a key aspect of policy towards immigrants. The idea is that by spreading immigrants the burden immigrants impose on natives is minimized, and the incentives of immigrants to adapt to native culture will be maximized. The first aspect has been modelled by the function $q(s)$ in the utility function of the natives; the second aspect is shaped by the term $s I^{s}$ in the culture term of the utility function of the immigrants. We have assumed that spreading policy does not involve costs for the government and is extremely effective. In particular, if the government pursues a maximal spreading policy, $s=0$, all immigrants will adapt to native culture, as $\hat{\rho}=1$ in that case. Given these (obviously non-realistic) assumptions, we investigate whether for a given number of immigrants and for a given spreading policy with $s>0$, the natives prefer the spreading policy to be intensified, i.e. to have a decrease in the values of the policy parameter $s$. Obviously, the regime is a determining factor again. In particular, under the unemployment regime, too few immigrants have decided to adapt with a too large capacity of the services sector as a consequence. Intensifying spreading policy, i.e. decreasing $s$, then implies an increase of the critical 
value for individual assimilation, $\tilde{\rho}$. Native utility will, therefore, unambiguously increase.

Under the rationing regime ${ }^{9}$, an increase of native utility will not be guaranteed by intensifying spreading policy. As the amount of services that can be consumed decreases by intensifying spreading policy, for some value of $s>0$, further decreases in $s$ will lead to lower native utility because of lower consumption. However, the positive effect on utility of the lower cultural burden immigrants impose, is the dominant effect, as we shall now show. Under rationing the effect of a spreading policy on native utility follows from:

$$
\frac{d V^{N}}{d s}=\left(\frac{\left(\delta w^{N}-(1+\delta) p \bar{g}\right)}{\left(w^{N}-p \bar{g}\right) \bar{g}}\right) \frac{d \bar{g}}{d s}-\frac{q(s)}{U} \frac{d U}{d s}-q^{\prime}(s) \log U \leq 0
$$

The first term indicates the effect spreading has on the utility of consuming goods and services. As spreading increases, the number of immigrants that adapt to native culture will increase, i.e $\frac{d \bar{g}}{d s}>0$. Therefore, obviously, spreading will have a negative effect on utility through the diminished consumption of services. The last two terms indicate the utility gain of the diminishing burden of cultural differences. Notice that the optimal number of immigrants with a given spreading policy is determined such that the cultural disutility of the marginal immigrant is equated to the marginal utility of consuming more services. As a result, if the optimal number of immigrants is allowed in, the first two terms of equation (15) exactly cancel out and only the term $-q^{\prime}(s) \log U$ remains ${ }^{10}$. Consequently, even if the optimal number of migrants is allowed in, intensifying the spreading policy will imply a utility gain as every non-assimilated worker causes a lower burden. The spreading policy, as we formulated it, should therefore be an effective and popular policy instrument to smooth the negative side effects of immigration.

\footnotetext{
${ }^{9}$ The same holds in case of equilibrium on the service market.
} 


\section{Subsidizing integration costs}

A second policy to increase the native culture choice by immigrants is by subsidizing the integration costs immigrants have to incur at integration. Asuming that the subsidies are paid for by the native workers, a more pronounced trade-off between gains and losses of this type of policy occurs. Unlike spreading policy, this type of policy can fail to be supported by the native voter if the unemployment regime prevails. In particular, this policy will not be supported if the marginal cost of the subsidy policy, consisting of the decrease in native net wage due to the subsidy, is larger than the marginal benefit of the subsidy policy, consisting in a decrease in the unemployment tax and a decrease in the cultural burden.

\section{Conclusions}

In this paper, we considered an economy where native voters determine the optimal number of immigrants. Immigrants can integrate into the native culture, but if they do not integrate they will be employed as unskilled workers in the service sector of the economy. We showed that, if cultural variables are an important factor in immigration policy, and voters take the market price for services as given, one should expect no equilibrium on the market for low-skill services. Equilibrium on the market for services, where private marginal benefits and marginal costs of consuming services are equal, would imply that the disutility of cultural distance between natives and non assimilated immigrants was not taken into account. As a result, political decision making on immigration will lead to a shortage in the supply of services produced by unskilled immigrants. Market forces will then engender a price increase of services implying that the number of migrants allowed on the basis of the initial price is no longer the optimal number, but has become too high. Moreover, the market for services may collapse if price increases imply that demand and supply for services will shift to the "shadow

${ }^{10}$ Formally, inserting from (11) $\frac{d V^{N}}{d I}=0$ into (15) and using the envelop theorem, we get: 
economy", in turn leading to high unemployment amongst non-assimilated migrants. Assuming that it is not possible to remove immigrants who were allowed in at an earlier stage, the obvious conclusion is that disutility of cultural distance in combination with market forces leads to a number of immigrants living in a destination country that is higher than the optimal number.

Apparently, immigration policy does not easily lead to an optimal inflow of immigrants. Other instruments should in that case be used to correct for the sub optimal decisions on immigration. One instrument that we considered was what we called a spreading policy. This policy, actually, is currently much debated in the European immigration countries in view of the existing "immigrant ghettos" in the big cities in those countries. From our simplified model we concluded that spreading is in many instances a policy that will be welfare improving for natives. Another policy instrument that can correct for the sub optimality of immigration policy is the provision of integration subsidies to non-assimilated immigrants. As this policy entails costs for the native workers, unanimous support for subsidizing immigrants who decide to integrate is not guaranteed.

We add that the results of our model are based on the presumption that voters are able to perceive the effects immigration has on the cultural nuisance caused by immigrants, and the effects of immigration on the utility of service consumption. We, however, did not assume that voters are able to infer the effect immigration has on the development of the market where unskilled immigrants work. This is in line with empirical evidence (Mayda, 2004), but relaxing this assumption will be the subject of further research.

\section{References}

Benhabib, J. (1996), On the political economy of migration, European Economic Review, vol. 40, pp. 17371743.

Dagevos, J. , M. Gijsberts, and C. van Praag, (2003), Report on Ethnic Minorities 2003. Education, work and sociocultural integration, Dutch Social Cultural Planning Office.

Dickens, W.T. and K. Lang (1985), A test of dual labor market theory, American Economic Review, vol. 75, Dickens

$$
\frac{d V^{N}}{d s}=-q^{\prime}(s) \log U<0
$$


Haupt, A. and W.Peters (1998), Public pensions and voting on immigration, Public Choice, vol. 95, pp. 403-413.

Hillman, A.L. (2002), Immigration and intergenerational transfers, in: H. Siebert, ed. Economic policy for aging societies, Springer, Berlijn.

Kónya, István (2003), The cultural assimilation of immigrants; an empirical investigation, Boston College.

Lazear, E.P., Culture and Language, The Journal of Political Economy, vol. 107, S95-S126.

Mansoorian, Arman and Gordon M. Myers (1993), Attachment to home and efficient purchases of population in a fiscal externality economy, Journal of Public Economics, vol. 52, pp. 117-132.

Mayda, A.M. (2004), Who is against immigration? A cross-country investigation of individual attitudes toward immgrants, IZA Bonn, discussion Paper 1115. 
Appendix. Calculation of $\frac{d \hat{\rho}}{d I}$

For the rationing regime the relationship between $\hat{\rho}$ and $I$ is given by equation (6). From that equation we can derive:

$$
\begin{gathered}
(1-\hat{\rho})^{\gamma} d \hat{\rho}-\gamma(1-\hat{\rho})^{\gamma-1} d \hat{\rho}=-\gamma \frac{\hat{\rho}(1-\hat{\rho})^{\gamma}}{I} d I-\frac{p}{s} I^{-\gamma}\left(\frac{w^{N}-K-w^{U}}{\left(w^{N}-K-p \bar{g}\right)\left(w^{u}-p \bar{g}\right)}\right) \\
\cdot\left(\frac{\partial \bar{g}}{\partial I} d I+\frac{\partial \bar{g}}{\partial \hat{\rho}} d \hat{\rho}\right)
\end{gathered}
$$

From the definition $\bar{g}=\frac{\beta U}{I+N}$ it follows that:

$$
\frac{\partial \bar{g}}{\partial I}=\frac{\beta(1-\hat{\rho}) N}{(I+N)^{2}} \text { and } \frac{\partial g}{\partial \hat{\rho}}=\frac{-\beta I}{I+N}
$$

Inserting (A.2) into (A.1) gives:

$$
\left\{(1-\hat{\rho})^{\gamma}\left(1-\frac{\gamma \hat{\rho}}{1-\hat{\rho}}\right)+\frac{\beta I^{1-\gamma}}{I+N} \frac{p \Gamma}{s}\right\} d \hat{\rho}=\left\{-\gamma \frac{\hat{\rho}(1-\hat{\rho})^{\gamma}}{I}+\frac{p \Gamma}{s} I^{-\gamma} \frac{\beta(1-\hat{\rho}) N}{(I+N)^{2}}\right\} \mathrm{dI}
$$

where $\Gamma=\frac{w^{N}-K-w^{U}}{\left(w^{N}-K-p \bar{g}\right)\left(w^{u}-p \bar{g}\right)}>0$. Assuming that $\gamma<\frac{1-\hat{\rho}}{\hat{\rho}}$ it follows that the terms in brackets at the left-hand side of (A.3) is positive. The term in brackets at the right-hand side will be negative if

$$
I>\frac{\gamma}{p \Gamma} \frac{(I+N)^{2}}{\beta(1-\hat{\rho}) N} \log \left(\frac{w^{N}-K-p \bar{g}}{\left(w^{u}-p \bar{g}\right)}\right)
$$

In words, $d \hat{\rho} / d I<0$ will hold if the number of non-assimilated immigrants $I$ is large enough. 


\section{CESifo Working Paper Series}

(for full list see www.cesifo.de)

1204 Elmer Sterken, The Role of the IFO Business Climate Indicator and Asset Prices in German Monetary Policy, May 2004

1205 Jan Jacobs and Jan-Egbert Sturm, Do Ifo Indicators Help Explain Revisions in German Industrial Production?, May 2004

1206 Ulrich Woitek, Real Wages and Business Cycle Asymmetries, May 2004

1207 Burkhard Heer and Alfred Maußner, Computation of Business Cycle Models: A Comparison of Numerical Methods, June 2004

1208 Costas Hadjiyiannis, Panos Hatzipanayotou, and Michael S. Michael, Pollution and Capital Tax Competition within a Regional Block, June 2004

1209 Stephan Klasen and Thorsten Nestmann, Population, Population Density, and Technological Change, June 2004

1210 Wolfgang Ochel, Welfare Time Limits in the United States - Experiences with a New Welfare-to-Work Approach, June 2004

1211 Luis H. R. Alvarez and Erkki Koskela, Taxation and Rotation Age under Stochastic Forest Stand Value, June 2004

1212 Bernard M. S. van Praag, The Connexion Between Old and New Approaches to Financial Satisfaction, June 2004

1213 Hendrik Hakenes and Martin Peitz, Selling Reputation When Going out of Business, June 2004

1214 Heikki Oksanen, Public Pensions in the National Accounts and Public Finance Targets, June 2004

1215 Ernst Fehr, Alexander Klein, and Klaus M. Schmidt, Contracts, Fairness, and Incentives, June 2004

1216 Amihai Glazer, Vesa Kanniainen, and Panu Poutvaara, Initial Luck, Status-Seeking and Snowballs Lead to Corporate Success and Failure, June 2004

1217 Bum J. Kim and Harris Schlesinger, Adverse Selection in an Insurance Market with Government-Guaranteed Subsistence Levels, June 2004

1218 Armin Falk, Charitable Giving as a Gift Exchange - Evidence from a Field Experiment, June 2004 
1219 Rainer Niemann, Asymmetric Taxation and Cross-Border Investment Decisions, June 2004

1220 Christian Holzner, Volker Meier, and Martin Werding, Time Limits on Welfare Use under Involuntary Unemployment, June 2004

1221 Michiel Evers, Ruud A. de Mooij, and Herman R. J. Vollebergh, Tax Competition under Minimum Rates: The Case of European Diesel Excises, June 2004

1222 S. Brock Blomberg and Gregory D. Hess, How Much Does Violence Tax Trade?, June 2004

1223 Josse Delfgaauw and Robert Dur, Incentives and Workers' Motivation in the Public Sector, June 2004

1224 Paul De Grauwe and Cláudia Costa Storti, The Effects of Monetary Policy: A MetaAnalysis, June 2004

1225 Volker Grossmann, How to Promote R\&D-based Growth? Public Education Expenditure on Scientists and Engineers versus R\&D Subsidies, June 2004

1226 Bart Cockx and Jean Ries, The Exhaustion of Unemployment Benefits in Belgium. Does it Enhance the Probability of Employment?, June 2004

1227 Bertil Holmlund, Sickness Absence and Search Unemployment, June 2004

1228 Klaas J. Beniers and Robert Dur, Politicians’ Motivation, Political Culture, and Electoral Competition, June 2004

1229 M. Hashem Pesaran, General Diagnostic Tests for Cross Section Dependence in Panels, July 2004

1230 Wladimir Raymond, Pierre Mohnen, Franz Palm, and Sybrand Schim van der Loeff, An Empirically-Based Taxonomy of Dutch Manufacturing: Innovation Policy Implications, July 2004

1231 Stefan Homburg, A New Approach to Optimal Commodity Taxation, July 2004

1232 Lorenzo Cappellari and Stephen P. Jenkins, Modelling Low Pay Transition Probabilities, Accounting for Panel Attrition, Non-Response, and Initial Conditions, July 2004

1233 Cheng Hsiao and M. Hashem Pesaran, Random Coefficient Panel Data Models, July 2004

1234 Frederick van der Ploeg, The Welfare State, Redistribution and the Economy, Reciprocal Altruism, Consumer Rivalry and Second Best, July 2004

1235 Thomas Fuchs and Ludger Woessmann, What Accounts for International Differences in Student Performance? A Re-Examination Using PISA Data, July 2004 
1236 Pascalis Raimondos-Møller and Alan D. Woodland, Measuring Tax Efficiency: A Tax Optimality Index, July 2004

1237 M. Hashem Pesaran, Davide Pettenuzzo, and Allan Timmermann, Forecasting Time Series Subject to Multiple Structural Breaks, July 2004

1238 Panu Poutvaara and Andreas Wagener, The Invisible Hand Plays Dice: Eventualities in Religious Markets, July 2004

1239 Eckhard Janeba, Moral Federalism, July 2004

1240 Robert S. Chirinko, Steven M. Fazzari, and Andrew P. Meyer, That Elusive Elasticity: A Long-Panel Approach to Estimating the Capital-Labor Substitution Elasticity, July 2004

1241 Hans Jarle Kind, Karen Helene Midelfart, Guttorm Schjelderup, Corporate Tax Systems, Multinational Enterprises, and Economic Integration, July 2004

1242 Vankatesh Bala and Ngo Van Long, International Trade and Cultural Diversity: A Model of Preference Selection, July 2004

1243 Wolfgang Eggert and Alfons J. Weichenrieder, On the Economics of Bottle Deposits, July 2004

1244 Sören Blomquist and Vidar Christiansen, Taxation and Heterogeneous Preferences, July 2004

1245 Rafael Lalive and Alois Stutzer, Approval of Equal Rights and Gender Differences in Well-Being, July 2004

1246 Paolo M. Panteghini, Wide vs. Narrow Tax Bases under Optimal Investment Timing, July 2004

1247 Marika Karanassou, Hector Sala, and Dennis J. Snower, Unemployment in the European Union: Institutions, Prices, and Growth, July 2004

1248 Engin Dalgic and Ngo Van Long, Corrupt Local Government as Resource Farmers: The Helping Hand and the Grabbing Hand, July 2004

1249 Francesco Giavazzi and Guido Tabellini, Economic and Political Liberalizations, July 2004

1250 Yin-Wong Cheung and Jude Yuen, An Output Perspective on a Northeast Asia Currency Union, August 2004

1251 Ralf Elsas, Frank Heinemann, and Marcel Tyrell, Multiple but Asymmetric Bank Financing: The Case of Relationship Lending, August 2004

1252 Steinar Holden, Wage Formation under Low Inflation, August 2004 
1253 Ngo Van Long and Gerhard Sorger, Insecure Property Rights and Growth: The Roles of Appropriation Costs, Wealth Effects, and Heterogeneity, August 2004

1254 Klaus Wälde and Pia Weiß, International Competition, Slim Firms and Wage Inequality, August 2004

1255 Jeremy S. S. Edwards and Alfons J. Weichenrieder, How Weak is the Weakest-Link Principle? On the Measurement of Firm Owners’ Control Rights, August 2004

1256 Guido Tabellini, The Role of the State in Economic Development, August 2004

1257 François Larmande and Jean-Pierre Ponssard, EVA and the Controllability-congruence Trade-off: An Empirical Investigation, August 2004

1258 Vesa Kanniainen and Jenni Pääkkönen, Anonymous Money, Moral Sentiments and Welfare, August 2004

1259 Panu Poutvaara and Andreas Wagener, Why is the Public Sector More Labor-Intensive? A Distortionary Tax Argument, August 2004

1260 Lars P. Feld and Stefan Voigt, Making Judges Independent - Some Proposals Regarding the Judiciary, August 2004

1261 Joop Hartog, Hans van Ophem, and Simona Maria Bajdechi, How Risky is Investment in Human Capital?, August 2004

1262 Thomas Eichner and Rüdiger Pethig, Efficient Nonanthropocentric Nature Protection, August 2004

1263 David-Jan Jansen and Jakob de Haan, Look Who's Talking: ECB Communication during the First Years of EMU, August 2004

1264 David F. Bradford, The X Tax in the World Economy, August 2004

1265 Hans-Werner Sinn, Migration, Social Standards and Replacement Incomes. How to Protect Low-income Workers in the Industrialized Countries against the Forces of Globalization and Market Integration, August 2004

1266 Wolfgang Leininger, Fending off one Means Fending off all: Evolutionary Stability in Submodular Games, August 2004

1267 Antoine Bommier and Bertrand Villeneuve, Risk Aversion and the Value of Risk to Life, September 2004

1268 Harrie A. A. Verbon and Lex Meijdam, Too Many Migrants, Too Few Services: A Model of Decision-making on Immigration and Integration with Cultural Distance, September 2004 